This item was submitted to Loughborough's Research Repository by the author.

Items in Figshare are protected by copyright, with all rights reserved, unless otherwise indicated.

\title{
Evidence of disturbed sleep and mood state in well-trained athletes during short-term intensified training with and without a high carbohydrate nutritional intervention
}

\section{PLEASE CITE THE PUBLISHED VERSION}

http://dx.doi.org/10.1080/02640414.2015.1085589

\section{PUBLISHER}

(C) Taylor and Francis

\section{VERSION}

AM (Accepted Manuscript)

\section{PUBLISHER STATEMENT}

This work is made available according to the conditions of the Creative Commons Attribution-NonCommercialNoDerivatives 4.0 International (CC BY-NC-ND 4.0) licence. Full details of this licence are available at: https://creativecommons.org/licenses/by-nc-nd/4.0/

\section{LICENCE}

CC BY-NC-ND 4.0

\section{REPOSITORY RECORD}

Killer, Sophie C., Ida S. Svendsen, A.E. Jeukendrup, and Michael Gleeson. 2019. "Evidence of Disturbed Sleep and Mood State in Well-trained Athletes During Short-term Intensified Training with and Without a High Carbohydrate Nutritional Intervention". figshare. https://hdl.handle.net/2134/20928. 


\title{
Evidence of disturbed sleep and mood state in well-trained athletes during short-term intensified training with and without a high carbohydrate nutritional intervention
}

\author{
Killer $S C^{l}$, Svendsen $I S^{l}$, Jeukendrup $A E^{1,2}$ and Gleeson $M^{l}$.
}

${ }^{1}$ School of Sport, Exercise and Health Sciences, Loughborough University, Loughborough, Leicestershire. LE11 3TU. UK.

${ }^{2}$ Gatorade Sport Science Institute, Loughborough University, Loughborough, Leicestershire. LE11 3TU. UK.

Contact Details: Sophie Killer

Sophie.Killer@outlook.com

British Athletics National Performance Institute

High Performance Athletics Centre (HiPAC)

Loughborough University

Loughborough

Leicestershire

LE11 3TU. UK

M: 07506689812

Key Words: Sleep, Nutrition, Athletes, Overtraining, 


\title{
Evidence of disturbed sleep and mood state in well-trained athletes during short-term intensified training with and without a high carbohydrate nutritional intervention
}

\begin{abstract}
$\underline{\text { Abstract }}$
Few studies have investigated the effects of exercise training on sleep physiology in welltrained athletes. We investigated changes in sleep markers, mood state and exercise performance in well-trained cyclists undergoing short-term intensified training and carbohydrate nutritional intervention. Thirteen highly-trained male cyclists (age: $25 \pm 6 y$, $\dot{\mathrm{V}} \mathrm{O}_{2 \max }: 72 \pm 5 \mathrm{ml} / \mathrm{kg} / \mathrm{min}$ ) participated in two 9-day periods of intensified training while undergoing a high $(\mathrm{HCHO})$ or moderate $(\mathrm{CON})$ carbohydrate nutritional intervention before, during and after training sessions. Sleep was measured each night via wristwatch actigraphy. Mood state questionnaires were completed daily. Performance was assessed with maximal oxygen uptake $\left(\mathrm{V}_{2 \max }\right)$. Percentage sleep time fell during intensified training $(87.9 \pm 1.5$ to $82.5 \pm 2.3 \% ; \mathrm{p}<0.05)$ despite an increase in time in bed $(456 \pm 50$ to $509 \pm 48 \mathrm{~min} ; \mathrm{p}=0.02)$. Sleep efficiency decreased during intensified training $(83.1 \pm 5.3$ to $77.8 \pm 8.6 \%$; $<<0.05)$. Actual sleep time was significantly higher in $\mathrm{CON}$ than $\mathrm{HCHO}$ throughout intensified training. Mood disturbance increased during intensified training and was higher in CON than HCHO $(\mathrm{p}<0.05)$. Performance in the $\dot{\mathrm{V}} \mathrm{O}_{2 \max }$ exercise protocol fell significantly with intensified training. The main findings of this study were that 9-days of intensified training in highly-trained cyclists resulted in significant and progressive declines in sleep quality, mood state and maximal exercise performance.
\end{abstract}

Keywords: Sleep, Cycling, Intensified training, Actigraphy.

Running Title: Disturbed sleep during short-term intensified training 


\section{$\underline{\text { Introduction }}$}

Periodisation with the application of the principle of overload training is a regular feature in an athletic training programme (Meeusen et al., 2013). These typically short-term 'intensified' periods occur in the forms of both training (training camps) and during busy competition schedules (tournaments, stage races etc.). The risk of under-recovery during these times is considerable and if the balance between appropriate training stress and adequate recovery is disrupted, a state of 'overreaching' may develop (Meeusen et al., 2013). Overreaching can be defined as a short term decrease in performance, which in the absence of recovery (and supercompensation) may develop into the more severe overtraining syndrome (Fry et al 1991). It is understood that several compounding factors, such as poor nutrition, inadequate sleep, illness and psychological stressors can augment the development of overreaching.

Sleep is considered to be the 'gold standard' post-exercise recovery procedure amongst athletes (Myllymaki et al., 2011; Samuels, 2008). During sleep, muscles are in a complete state of relaxation allowing effective myofibre restoration. This process is further enhanced by the release of growth hormone from the pituitary gland during the night which stimulates protein synthesis and has important effects on muscle and bone growth, repair and adaptation (Davenne, 2009). When sleep quality or duration (or combinations of the two) become compromised, there can be a significant detrimental impact on human functioning and mood state (Pilcher \& Huffcutt, 1996). Sleep deprivation studies in athletes have reported increased errors, impaired decision making, reduced maximal power, increased fatigue (Reilly \& Edwards, 2007) and an attenuation of the ability to perform maximal exercise, as both aerobic and anaerobic pathways are affected (Davenne, 2009).

Research has shown numerous beneficial effects of sleep on exercise performance, and equally several studies have reported positive effects of exercise on sleep physiology (Kubitzet al, 1996; Youngstedt et al, 1997). Regular physical activity has been shown to 
improve self-reported sleep compared with a sedentary lifestyle (Davenne, 2009; Driver \& Taylor, 2000; Youngstedt \& Kline, 2006). It is also understood that exercise improves mood state (Blumenthal et al., 1999; Dunn et al, 2005), which can be an additional factor in improving (or disturbing) sleep (Uchida et al., 2012). Acute exercise in the evenings has been suggested to have positive effects on sleep (Flausino et al, 2012; O'Connor et al, 1998; Youngstedt et al., 1997), especially when it is of moderate intensity (Vuori et al, 1988). However, it has been proposed that high-intensity exhaustive exercise may be disruptive to sleep by causing decreased rapid eye movement (REM) sleep and increasing wakefulness (Driver \& Taylor, 2000). It has also reported that elite athletes experience poorer sleep quality than age-matched sedentary individuals, but still remain within the range for healthy sleep (Leeder et al, 2012). Research to date suggests that interactions between sleep and exercise do exist, but are not yet fully understood.

Relatively few studies have investigated the effects of exercise training on sleep physiology in athletic populations (Souissi et al., 2011). Thus, the manner in which sleep duration and efficiency are affected by strenuous exercise and training days remains unclear (Fietze et al., 2009). Previous sleep research has primarily focused on physically active groups of 'good sleepers' whereby the exercise stress is low and the margin for sleep improvement is relatively small (ceiling effect) (Driver \& Taylor, 2000). A small collection of studies have reported sleeping behaviours in athletes, finding evidence for sleep disturbance during busy times in the season (Taylor et al, 1997) and reduced sleep efficiency, duration and immobile time when diagnosed as overreached (Hausswirth et al, 2014). Conversely, increases in slow wave sleep during busy periods have been reported, suggesting improved sleep quality and thereby supporting the restorative theory of sleep (Oswald, 1970).

The effects of nutritional interventions on various sleep parameters have been investigated over recent years. Aside from testing numerous herbal extracts, research has focussed on 
how ingestion of different macronutrients may impact sleep. A small number of studies have investigated the effects of different macronutrients and/or total energy consumed prior to bedtime (Afaghi et al, 2008; Hartmann et al, 1979; Porter \& Horne, 1981; Zammit et al, 1995) or overall high carbohydrate vs. low carbohydrate diets (Phillips et al., 1975) on sleep quality. The data are limited and equivocal, likely due to varying study designs; however, based on the available information, it has been suggested that reduced caloric intakes may result in poorer sleep (S. Halson, 2013). No studies to date have investigated the effects of targeted nutrition interventions during exercise on sleep parameters. The timing of nutrient intake to ensure high availability for performance and recovery is of great importance to athletes, but how this may impact sleep and thus, longer term recovery remains unknown.

It has been established that carbohydrate feeding before and during exercise can provide a substrate for muscle and brain during exercise and can delay muscle fatigue and enhance performance (For reviews, see (A. E. Jeukendrup, 2013; A. Jeukendrup, 2014)).. Sherman and colleagues investigated the effects of a high (10 g/kg/day) vs. moderate $(5 \mathrm{~g} / \mathrm{kg} / \mathrm{day})$ carbohydrate diets on muscle glycogen levels during 7 days of intense cycling (Sherman et al, 1993). The authors reported that the moderate carbohydrate diet resulted in a significant reduction in muscle glycogen over time (30-36\%) compared with the high carbohydrate diet (Sherman et al., 1993). Interestingly however, no difference in a maximal test to exhaustion was observed after the 7-day intensified training period compared to pre-trial, or differences between carbohydrate groups. Recent studies have shown that high carbohydrate intakes (8.5-9.4 $\mathrm{g} / \mathrm{kg} /$ day) during periods of intensified training help to attenuate the decline in endurance performance and mood state compared to normal/moderate carbohydrate intakes (5.4-6.4 g/kg/day) (Achten et al., 2004; Halson et al, 2004). The current carbohydrate guidelines for athletes undergoing a high volume endurance training programme range from 6-10 g/kg/day (American Dietetics Association, Dietitians of Canada, 2009; Maughan \& Burke, 2012). During endurance exercise lasting longer than $1 \mathrm{~h}$, recommended intakes range from 30-90 g/h carbohydrate (A. Jeukendrup, 2014; A. E. Jeukendrup, 2011; Maughan 
\& Burke, 2012) or 30-60 g/h carbohydrate (American Dietetics Association, Dietitians of Canada, 2009). In practice, however, many athletes actually consume significantly lower intakes than recommended (Burke et al, 2001) due to a variety of factors including; restricted access to foods/fluids due to the nature of the sport, attempts to reduce gastrointestinal discomfort or concerns about energy balance and a desire to maintain low body fat levels (Garth \& Burke, 2013).

Given the known restorative qualities of sleep for athletic performance, it is of great interest to understand how periods of intensified training affect sleep quality in trained athletes. It is possible that training will elicit a level of stress that induces fatigue and the body responds with enhanced or at least sufficient sleep (restorative theory of sleep) or alternatively the combination of physiological and psychological stresses associated with intensified training programmes will result in a reduction in sleep efficiency and/or duration. It is of further interest to understand how a training-specific high carbohydrate nutritional intervention may impact not only performance and mood state, but subsequent sleep parameters compared with a moderate carbohydrate alternative. Interestingly, sleep deprivation can slow glucose metabolism (reducing the rate of glucose disposal and blunting the insulin response) by as much as $30-40 \%$ (Spiegel et al, 1999), which has implications for glycogen resynthesis for athletes which could hinder subsequent exercise performance. Therefore, there may be important links between sleep, exercise and nutrition that are yet to be understood.

The aims of this study were two-fold. Firstly, we aimed to investigate the impact of 9 days of intensified training in well-trained cyclists on sleep quality, through analysis of nocturnal actigraphy, and mood state compared with baseline measurements. Secondly, we aimed to understand the effects of a high vs. moderate carbohydrate intervention on exercise performance, sleep parameters and mood state during intensified training. Ultimately, we hoped to gain an insight into the physical and psychological changes that occur in highly trained athletes undergoing relatively short periods of intensified training. It was hypothesised that intensified would result in some level of sleep disturbance in these athletes 
and that the high carbohydrate intervention may attenuate some of this disruption to sleep and help maintain performance and mood state in line with previous research.

This study was part of a larger project where we also studied effects on immune and endocrine systems and early markers or indicators of overreaching. 


\section{Methods}

\section{Participants}

Thirteen highly-trained cyclists (age: $25.0 \pm 5.8 \mathrm{y}$, maximal oxygen uptake $\left(\dot{\mathrm{V}}_{2 \max }\right): 72.2 \pm$ $4.9 \mathrm{ml} / \mathrm{kg} / \mathrm{min}$, height: $178.3 \pm 3.9 \mathrm{~cm}$, body mass: $69.8 \pm 6.3 \mathrm{~kg}$, body fat: $13.4 \pm 4.1 \%$ ) completed the study. Participants were included if they had a competitive cycling history of at least $3 \mathrm{y}$, were currently cycling at least three times per week for a minimum of $2 \mathrm{~h} / \mathrm{day}$ and had a $\dot{V} O_{2 \max }$ of $\geq 65 \mathrm{~mL} / \mathrm{kg} / \mathrm{min}$. Participants were excluded from the study if they were currently suffering from any cycling-related injuries or had experienced any symptoms of URTI in the four weeks prior to the study. Fifteen participants were recruited, two of which were unable to complete the study due to individual circumstances preventing them from training. All participants were informed of the purposes of the study and the risks associated with the procedures. Written informed consent was obtained from each participant and a general health questionnaire was completed before the study commenced. The study was approved by the Loughborough University ethical advisory committee.

\section{Experimental Design}

In a double blind, randomised and counterbalanced, cross-over design, participants underwent two 9-day periods of intensified training (IT) while ingesting one of two nutritional interventions. During the high carbohydrate intervention (HCHO), participants consumed carbohydrate beverages at intakes in line with current ACSM guidelines (American Dietetics Association, Dietitians of Canada, 2009) before and during exercise, followed by a high carbohydrate and protein recovery beverage in the immediate recovery period $(<10$ min post-training). During the control condition $(\mathrm{CON})$, participants were provided with lower carbohydrate concentration beverages before, during and after training. No protein was provided in the control condition. Prior to their first trial, participants completed a 2-week pre-trial period to allow baseline measurements to be taken and familiarisation with study procedures. At the beginning and end of each period of IT, 
participants underwent a $\dot{\mathrm{VO}}_{2 \max }$ test to assess performance. A 10-day washout period separated the two trials. Sleep was quantified each night throughout the trial with wrist watch actigraphy.

\section{Pre-trial tests}

During their first visit, participants underwent an incremental cycle test to exhaustion on an electronically braked ergometer (Lode Excalibur Sport, Groningen, Netherlands) to determine eligibility to participate. Breath by breath expiratory gases were analysed automatically throughout the test with a Moxus metabolic systems analyser (AEI Technologies Inc., Naperville, IL, USA). Heart rate was recorded continually using short range telemetry (Polar RS800CX, Polar, Kempele, Finland) and ratings of perceived exertion were recorded from participants during the final minute of each stage. If participants achieved a $\dot{\mathrm{V}} \mathrm{O}_{2 \max }$ of $\geq 65 \mathrm{ml} / \mathrm{kg} / \mathrm{min}$ and were suitable according to all other criteria, they were included in the study. Following this, each suitable participant completed a 2-week pre-trial training diary, including mood-state questionnaires and a 3-day weighed diet diary. Participants were provided with heart rate (HR) monitors, SRM power meters (SRM Shimano DA7900 PowerMeter) and an actiwatch (MotionWatch 8, CamNtech, Cambridgeshire, UK) and requested to train according to their normal programmes during this phase. Body composition was determined by DXA at the Gatorade Sports Science Laboratory at Loughborough University.

\section{Training Procedures}

Each IT programme was based on the participants' pre-trial training diaries and discussed with each individual athlete. Training volume and intensity (time spent in the highest 3 heart rate (HR) zones) was increased 2.5-fold from baseline. HR zones were calculated from maximum HR achieved during the $\dot{\mathrm{V}} \mathrm{O}_{2 \text { max }}$ test on day 1 of IT. Five zones were devised, based on previous research within our group (Halson et al., 2002; Halson et al., 2004) and 
expressed as a percentage of maximum HR; Zone 1: $<69 \%$, Zone 2: $69 \%-81 \%$, Zone 3: $82 \%-87 \%$, Zone 4: $88 \%$ - 94\%, Zone 5: >94\%. Power zones were used as an additional guideline for the required intensity of each training session; calculated as a percentage of Watt max obtained on participants first $\mathrm{V}_{2 \max }$ test of each trial. SRM power meters (SRM Shimano DA7900 PowerMeter) were fitted to each participant's bicycle to enable the monitoring of power output from all sessions. Participants were also provided with a HR belt to use specifically for training (Suunto ANT, Amer Sports Corporation, Finland). Participants were responsible for uploading data files (power and HR) after each training session via secure online training software (Training Peaks Ltd.). This enabled the researchers to monitor training sessions that were not performed in the laboratory. In addition, participants completed a paper training diary during each day throughout the whole study period which consisted of a record of all training sessions, environmental conditions and perceived intensity.

\section{Sleep Measurement}

Participants were fitted with an actiwatch (MotionWatch 8, CamNtech, Cambridgeshire, UK) during their pre-trial period to obtain baseline sleep scores using wrist watch actigraphy. Baseline data were collected for 5 consecutive nights (mean). Participants continued to wear the actiwatch each night for the duration of the study. The actiwatch is a light weight, waterproof, wrist-worn tri-axial actigraph designed to provide an empirical measurement of movement throughout the night. The actiwatch uses activity counts to apply published algorithms for measurement on actigraphy data, resulting in a reliable and valid method for monitoring sleep (Sadeh, 2011). Data were sampled at $50 \mathrm{~Hz}$ and processed into 30s epochs. Sleep measurement included; time in bed (TB), actual sleep time (AST), percentage sleep time (ST\%) expressed as a percentage of assumed sleep time, sleep efficiency (SE) defined as actual sleep time expressed as a percentage of time in bed, sleep onset latency (SOL), wake bouts (WB) defined as the number of continuous sections 
categorised as awake in the epoch-by-epoch wake/sleep categorisation, mobile time (MT) expressed as a percentage of assumed sleep time, and the fragmentation index (FI) defined as the sum of the mobile time $(\%)$ and the immobile bouts $<=1 \mathrm{~min}(\%)$. The fragmentation index is an indication of the degree of fragmentation of the sleep period, and can be used as an indication of sleep quality. Sleep data were collected each night and grouped into four quarters of IT for statistical analysis; sleep period 1 (nights 1-2), 2 (nights 3-4), 3 (nights 56) and 4 (nights 7-8). In addition, participants completed a daily sleep diary, reporting morning resting HR, time to bed and wake up time. Participants were provided with a HR monitor to measure overnight heart rate (Polar RS800CX, Polar, Kempele, Finland). Participants were instructed to fit the HR chest strap when preparing for bed to ensure a strong signal was detected by the watch. HR recordings began after turning lights out for the night. Upon waking in the morning, participants were requested to note down their resting heart rate before stopping the recording session and getting out of bed.

\section{Mood State}

The Profile of Mood State shortened version (POMS-24) and the Daily Analysis of Lifestyle Demands on Athletes (DALDA) were completed daily. In addition, the full 65 item POMS questionnaire (POMS-65) was completed on days 1, 3, 6 and 9. Global mood state (GMS) was calculated from POMS questionnaires by summing the five negative measures of affect (tension, depression, anger, fatigue and confusion) and subtracting scores for vigour. Total mood disturbance (TMB) was monitored throughout IT by changes in global mood state. The DALDA questionnaire identifies the sources (part A) and symptoms (part B) of stress for athletes. Changes in total mood disturbance were determined from DALDA B by analysing changes in the number of ' $\mathrm{a}$ ' (worse than normal) and ' $\mathrm{c}$ ' (better than normal) scores.

Nutritional Intervention and Assessment of Dietary Intake 
Participants and lead investigators were blind to the intervention order. During IT, participants ingested either high ( $\mathrm{HCHO})$ or control $(\mathrm{CON})$ nutritional beverage before, during and after each training session. Participants were instructed to consume their normal diet throughout each training period and keep their diets as similar as possible between the two conditions. In addition, participants completed a weighed diet diary each day through the entirety of each trial and at select time points during the pre-trial and washout periods. Evening meals consumed before the performance tests were replicated as closely as possible each time, across both conditions. Caffeine was not permitted for $12 \mathrm{~h}$ before performance testing. Participants consumed a pre-exercise beverage within 15 min of starting each training session. Pre-exercise beverages were taste matched carbohydrate solutions (118 $\mathrm{mL}$ ); containing $24 \mathrm{~g}$ or $2 \mathrm{~g}$ carbohydrate for $\mathrm{HCHO}$ and $\mathrm{CON}$, respectively. During exercise, participants consumed $1 \mathrm{~L}$ of a taste matched carbohydrate-electrolyte solution per hour of exercise; containing $60 \mathrm{~g}(6 \mathrm{~m} / \mathrm{v} \%)$ or $20 \mathrm{~g}(2 \mathrm{~m} / \mathrm{v} \%)$ carbohydrate for $\mathrm{HCHO}$ and CON conditions, respectively. Following exercise, participants were provided with recovery nutrition; both trials received a carbohydrate-electrolyte solution (30 g vs $10 \mathrm{~g}$ carbohydrate for $\mathrm{HCHO}$ and $\mathrm{CON}$, respectively) in addition to a recovery product; a beverage during the $\mathrm{HCHO}$ condition and a placebo tablet in $\mathrm{CON}$. The $\mathrm{HCHO}$ recovery beverage contained 14 g CHO and $17 \mathrm{~g}$ protein. The CON placebo tablet contained only $1 \mathrm{~g}$ cellulose. Participants were informed that the variation in the nutritional intervention was in the recovery nutrition formulation, either tablet or beverage. When questioned after the study, no participants reported noticing any differences between carbohydrate beverages or that the intervention involved the manipulation of carbohydrate ingestion.

\section{Performance Testing}

Participants underwent a graded exercise test to exhaustion on an electronically braked ergometer (Lode Excalibur Sport, Groningen, Netherlands) at the beginning and end of each period of IT. Participants arrived at the laboratory at the same time for each test (between 
06:30-08:00) following an overnight fast of $\geq 8 \mathrm{~h}$. Results were used to determine maximal $\dot{\mathrm{V}} \mathrm{O}_{2}$, HR and power output $\left(\mathrm{W}_{\max }\right)$. No warm-up time was permitted prior to testing; however, the test began at $60 \mathrm{~W}$ and power increased by $35 \mathrm{~W}$ every $3 \mathrm{~min}$ until volitional exhaustion. Expiratory gases were collected continually throughout the test and each breath was analysed automatically with a Moxus metabolic systems analyser (AEI Technologies Inc., Naperville, IL, USA). Heart rate was recorded continually using short range telemetry (Polar RS800CX, Polar, Kempele, Finland) and ratings of perceived exertion were recorded from participants during the final minute of each stage.

$\mathrm{W}_{\max }$ was calculated with the following equation:

$$
\mathrm{W}_{\text {max }}=\mathrm{W}_{\text {final }}+(t / \mathrm{T}) \cdot \mathrm{W}_{\text {inc }}
$$

$\mathrm{W}_{\text {final }}$ is the power output $(\mathrm{W})$ of the final completed stage, $t$ is the time achieved in the final uncompleted stage (s), $\mathrm{T}$ is the duration of each stage $(180 \mathrm{~s})$ and $\mathrm{W}_{\text {inc }}$ is the workload increment $(35 \mathrm{~W})$.

\section{Statistical Analysis}

All data were analysed using statistical software (IBM SPSS Statistics 21) and are presented in text as Mean \pm Standard Deviation. Changes in performance parameters, mood state and sleep parameters were analysed using a 2-way repeated measures analysis of variance (ANOVA). A Bonferroni adjustment was included into the analysis to correct for multiple comparisons. Data that were found to be significantly non-normal were log transformed prior to analysis. Between trial and pre- to post-IT changes in performance parameters were determined using an independent samples t-test. Trial order effects were tested using an independent samples t-test to compare group means. The level of significance was set at $\mathrm{p}<0.05$. 


\section{$\underline{\text { Results }}$}

\section{Nutritional Assessment}

Total energy intake (EI) and dietary carbohydrate intake were significantly higher in $\mathrm{HCHO}$ than $\operatorname{CON}(4148 \pm 766$ vs $3501 \pm 616 \mathrm{kcal}$ and $9.9 \pm 1.5$ vs $7.4 \pm 1.6 \mathrm{~g}$ carbohydrate, respectively; $\mathrm{p}<0.05$ ) and increased significantly in both conditions compared with pre-trial intakes. Dietary protein intake was significantly higher in $\mathrm{HCHO}$ than $\mathrm{CON}(2.1 \pm 0.5$ vs 1.7 $\pm 0.4 \mathrm{~g} / \mathrm{kg}$ protein; $\mathrm{p}<0.05)$ and compared with pre-trial intakes $(1.7 \pm 0.5 \mathrm{~g} / \mathrm{kg}$ protein; $\mathrm{p}<0.05)$. No changes in protein were reported between pre-trial and CON. No differences in dietary fat intakes were observed between $\mathrm{CON}$ and $\mathrm{HCHO}(1.3 \pm 0.4$ vs $1.5 \pm 0.4 \mathrm{~g} / \mathrm{kg}$; $\mathrm{p}>0.05)$. Fat intake was significantly higher in CON than pre-trial intakes $(\mathrm{p}<0.05)$.

\section{Intensified Training}

Weekly training volume increased by $153 \%$ during IT compared with pre-trial baseline training $(9.3 \pm 2.4$ to $23.5 \pm 3.4 \mathrm{~h} /$ week; $\mathrm{p}<0.001)$. Total time spent training during the 9 days of IT was $30.2 \pm 4.4 \mathrm{~h}$. Weekly training intensity increased by $146 \%$ during IT compared with pre-trial baseline training $(2.6 \pm 2.5$ to $6.5 \pm 4.0 \mathrm{~h} /$ week spent training in zone 3 or above ( $\geq 82 \%$ HRmax); $<<0.01)$. Total time spent training above $82 \%$ HRmax during IT was $8.3 \pm 5.2 \mathrm{~h}$.

\section{Performance Data}

Data from the incremental tests to exhaustion revealed a significant reduction performance following IT in both conditions ( $\mathrm{p}<0.05)$, with no differences between conditions; $\mathrm{W}_{\max }(391$ \pm 37 to $375 \pm 38 \mathrm{~W})$ : maximum $\mathrm{HR}(190 \pm 10$ to $179 \pm 8 \mathrm{bpm})$ and completion time $(31: 15$ 
\pm 03:12 to 30:00 \pm 03:30). However, IT did not result in a significant reduction in absolute $\dot{\mathrm{V}} \mathrm{O}_{2 \max }: 4.91 \pm 0.48$ to $4.86 \pm 0.48 \mathrm{~L} / \mathrm{min}$ for pre- and post-IT, respectively.

\section{Sleep Measurements}

IT resulted in a significant increase in time in bed $(456 \pm 50$ to $509 \pm 48 \mathrm{~min} ; \mathrm{p}=0.02)$ (figure 1) with a non-significant increase in actual sleep time and resultant decrease in percentage sleep time $(87.9 \pm 1.5$ to $82.5 \pm 2.3 \%)$. Overall, actual sleep time was significantly higher in CON than HCHO throughout IT (396 \pm 11 vs. $377 \pm 16 \mathrm{~min} ; \mathrm{p}=0.03$ ). No trial order effects were observed between measured sleep parameters. Ten participants successfully recorded complete sets of sleep files from both trials, therefore the number of participants included in the sleep analysis is ten.

There was a significant progressive increase in the number of wake bouts during the night ( $28.1 \pm 2.8$ to $35.0 \pm 2.6$ bouts; $\mathrm{p}=0.03$ ) (figure 1$)$ and movement time $(7.7 \pm 0.9$ to $12.7 \pm$ $1.6 \% ; \mathrm{p}<0.01)$ throughout IT and a resultant increase in sleep fragmentation index $(\mathrm{p}=0.02)$ (figure 1).

$$
\text { ****Insert Figure } 1 \text { here**** }
$$

Sleep efficiency decreased significantly with time from beginning to end of IT (83.1 \pm 5.3 to $77.8 \pm 8.6 \%$; $p<0.05$ ) (figure 2). No changes were observed in sleep onset latency with IT, or between conditions.

$$
\text { ****Insert Figure } 2 \text { here } * * * *
$$

\section{Mood State Questionnaires}

Daily records of POMS-24 showed a continual increase in total mood disturbance throughout IT $(\mathrm{p}<0.01)$ (figure 3). Overall, total mood disturbance was significantly higher in CON than HCHO throughout the period of IT ( $\mathrm{p}=0.03$ ). Data from POMS-65, recorded 
every three days supported findings from the shortened version, showing a significant increase in total mood disturbance with time $(\mathrm{p}<0.05)$ and total mood disturbance was significantly higher in $\mathrm{CON}$ than $\mathrm{HCHO}$ at day $9(\mathrm{p}=0.03)$.

Results from DALDA questionnaire also indicated a significant overall disturbance in mood state, with an increase in section B 'a Scores' (figure 4) and a decrease in number of 'c Scores' with IT $(\mathrm{p}<0.05)$.

$$
\text { ****Insert Figures } 3 \text { and } 4 \text { here }{ }^{* * * *}
$$

Morning HR did not change significantly from beginning to end of IT. However, following a non-significant increase during the first quarter of IT in HCHO, HR tended to fall by the end of IT ( $\mathrm{p}=0.08)$. Post hoc analysis shows morning HR was significantly higher during days 56 in $\mathrm{CON}$ than $\mathrm{HCHO}$ ( $\mathrm{p}=0.01$ ); however, no main effect for condition was observed (figure $5)$.

$$
* * * * \text { Insert Figure } 5 \text { here } * * * *
$$

Overnight HR proved difficult to record, with significant losses of signal throughout the night. Complete data sets were collected from 4 participants and therefore have not been included in the final analysis. 


\section{Discussion}

The aims of the present study were to investigate the impact of 9 days of intensified training in well-trained cyclists on subjective sleep quality and mood state. Furthermore, we aimed to determine the effects of a high $\mathrm{CHO}$ nutritional intervention provided immediately before, during and after each training session, compared with a moderate $\mathrm{CHO}$ control on these parameters. The main finding of this study was that as little as 9 days of intensified training in highly-trained cyclists resulted in a significant and progressive decline in sleep quality, as assessed with actigraphy. In addition, we observed significant declines in mood state and maximal exercise capacity during a test to exhaustion. The high $\mathrm{CHO}$ nutritional intervention reduced some, but not all of the detrimental effects of IT.

The cycle of successful training must involve overload to a state of acute fatigue, followed by a period of rest. The results of such training are positive adaptations and improvements in performance (Meeusen et al., 2013). However, if overload training is not followed by sufficient rest, overreaching may occur. Overreaching has recently been defined as an accumulation of training and non-training stress resulting in short-term declines in physical performance with or without related physical and psychological symptoms (Meeusen et al., 2013). Performance capacity may take several days to several weeks of recovery to be fully restored. Sleep is an essential aspect of recovery and fatigue management (Myllymaki et al., 2011; Samuels, 2008). Disturbed sleep is often reported as both a contributor (Jurimae $=$ et al, 2004; Kuipers \& Keizer, 1988; Meeusen et al., 2013) and/or symptom of overreaching (Kentta \& Hassmen, 1998; Kuipers \& Keizer, 1988; Meeusen et al., 2013; Tayloret al, 1997), however there is a paucity of data to support either of these claims. Whilst a full state of overreaching may not have occurred in all of the participants in this study, many reported performance decrements and declined mood states during the period of IT, thus these findings support the anecdotal evidence and suggested hypothesis that IT, leading to overreaching can result in compromised sleep quality. It is of interest that these athletes increased the time they spent in bed (TB) during IT, suggesting that they were exhibiting 
symptoms of fatigue; and although the increased time in bed did not result in an increase in actual sleep time, it did compensate for impaired sleep quality as such that actual sleep time was not significantly changed during IT. Our data revealed that sleep efficiency was significantly reduced during the intensified training period from $83.1 \pm 5.3$ to $77.8 \pm 8.6 \%$. Furthermore, there was an increase in the number of wake bouts throughout the night and overall a more fragmented sleep period. In addition, the cyclists experienced significant disruptions to mood state, reporting increased tension, anger, fatigue, confusion, depression and increased feelings and symptoms of stress.

These findings contradict the theory that sleep is proportional to restorative needs and instead fall in line with results from similar studies that have reported impaired sleep efficiency during periods of intense training (Fietze et al., 2009) or when athletes have become overreached (Hausswirth et al., 2014). However, it is interesting to note that actual sleep time was significantly higher during IT in $\mathrm{CON}$ than $\mathrm{HCHO}$, which may indicate an increased requirement for recovery and/or expression of fatigue. It is understood that some forms of training are known to result in detrimental psychological effects (Raglin \& Morgan, 1994) and that mood disturbances increase in a progressive manner with step-wise increases in training load (Morgan et al, 1987). Significant increases in POMS-24 and POMS-65 total mood disturbance were observed in both conditions as a result of IT. Furthermore, there was a significant increase in DALDA scores for symptoms of stress being 'worse than normal'. These findings support the work of previous research into the psychological impacts of intensified training, overreaching and overtraining in athletes (Achten et al., 2004; Halson et al., 2002; Halson et al, 2003; Halson et al., 2004; Jeukendrup et al, 1992; Morgan et al., 1987; Morgan et al, 1988; Witard et al, 2011).

A high carbohydrate intake during intensified training programmes has been suggested to help maintain performance and mood state (Achten et al., 2004; Halson et al., 2004; Jacobs \& Sherman, 1999). The findings of this study support these suggestions; with data from the CON condition showing significantly higher total mood disturbance throughout IT (daily 
POMS-24) and significantly higher total mood disturbance in $\mathrm{CON}$ than $\mathrm{HCHO}$ at the end of IT (POMS-65). No differences between conditions were observed from the DALDA, suggesting that the POMS questionnaire may be a more sensitive measure of mood state. Interestingly, this study found no differences in $\dot{\mathrm{VO}}_{2 \max }$ test results between the $\mathrm{HCHO}$ and CON conditions, with both reporting significant declines in peak power, completion time and maximum HR. Whilst these findings do not support the results of the aforementioned studies, these data are in agreement with the findings of Sherman and colleagues (Sherman et al., 1993) who investigated the effects of moderate vs. high carbohydrate diets on training capacity and high intensity exercise performance. These authors reported that although intensified training on a moderate carbohydrate diet resulted in significant reductions in muscle glycogen compared with the high carbohydrate diet, no differences in high intensity exercise performance were observed.

It is interesting to note that the small addition of protein to the recovery supplement in the $\mathrm{HCHO}$ condition resulted in a significant overall increase in dietary protein in $\mathrm{HCHO}$ compared with CON. A recent study found that high dietary protein intakes ( $3 \mathrm{~g} / \mathrm{kg} / \mathrm{day})$, especially when consumed immediately after exercise, attenuates mood state disturbances and endurance performance decrements compared to a moderate intake $(1.5 \mathrm{~g} / \mathrm{kg} / \mathrm{d})$ following a short term period of intensified training (Witard et al., 2011). Although protein intakes during $\mathrm{HCHO}$ were substantially lower than in the study of Witard and colleagues (3 $\mathrm{g} / \mathrm{kg} / \mathrm{day}$ vs. $2.1 \mathrm{~g} / \mathrm{kg} / \mathrm{day}$ ), it may be possible that the timing of protein ingestion after exercise provided a stimulus for recovery that was not available during CON. The additional protein ingested following each session in $\mathrm{HCHO}$ may have contributed to the small differences observed between $\mathrm{HCHO}$ and $\mathrm{CON}$ and should therefore not be overlooked.

To our knowledge, our study is the first to investigate the effects of intensified training with a high carbohydrate nutritional intervention on sleep parameters. Despite intensified training having a detrimental effect across a range of sleep parameters, the only difference between conditions observed was significantly longer actual sleep time in CON compared with 
HCHO (396 \pm 11 vs. $377 \pm 16 \mathrm{~min})$. It was also observed that during the third quarter of IT (days 5-6), HR was significantly higher in CON than HCHO (52 \pm 9 vs. $46 \pm 7$ bpm). These, together, could indicate a greater level of fatigue in the CON condition and that the high carbohydrate availability during exercise in the HCHO trial may have provided a level of protection against the changes in sympathetic nervous activity that are thought to be linked to the OTS (Israel 1976).

\section{$\underline{\text { Conclusions }}$}

Overall, these findings suggest that relatively short periods of intensified training, similar to a training camp, can result in significant disruptions on sleep quality and mood state. It is interesting to note that high intensity exercise performance decreased significantly following IT independent of nutritional intervention, which suggests athletes may have been exhibiting early signs of overreaching. The athletes in this study were not aware that the two trials involved varying $\mathrm{CHO}$ intakes, therefore it is unlikely that differences observed in mood state were a result of knowing that they were exercising with insufficient energy replacement (according to the current ACSM guidelines (American Dietetics Association, Dietitians of Canada, 2009)). With sleep and passive rest providing an important form of recovery, athletes undergoing such programmes should plan ahead with their coaches to ensure sleep is optimised. Strategies to enhance sleep during these times may include improving sleep hygiene before bedtime, ensuring adequate time in bed and incorporating time to nap into the day routine. 
References

Achten, J., Halson, S. L., Moseley, L., Rayson, M. P., Casey, A., \& Jeukendrup, A. E. (2004). Higher dietary carbohydrate content during intensified running training results in better maintenance of performance and mood state. Journal of Applied Physiology (Bethesda, Md.: 1985), 96(4), 1331-1340. doi:10.1152/japplphysiol.00973.2003 [doi]

Afaghi, A., O'Connor, H., \& Chow, C. M. (2008). Acute effects of the very low carbohydrate diet on sleep indices. Nutritional Neuroscience, 11(4), 146-154. doi:10.1179/147683008X301540 [doi]

American Dietetics Association, Dieticians of Canada. (2009). Nutrition and athletic performance, joint position statement. Medicine and Science in Sport and Exercise, doi:10.1249/MSS.0b013e318190eb86

Blumenthal, J. A., Babyak, M. A., Moore, K. A., Craighead, W. E., Herman, S., Khatri, P., . . Krishnan, K. R. (1999). Effects of exercise training on older patients with major depression. Archives of Internal Medicine, 159(19), 2349-2356.

Burke, L. M., Cox, G. R., Culmmings, N. K., \& Desbrow, B. (2001). Guidelines for daily carbohydrate intake: Do athletes achieve them? Sports Medicine (Auckland, N.Z.), 31(4), 267-299.

Davenne, D. (2009). Sleep of athletes - problems and possible solutions Biological Rhythm Research, 40(1), 45-52.

Driver, H. S., \& Taylor, S. R. (2000). Exercise and sleep. Sleep Medicine Reviews, 4(4), 387-402. doi:S1087-0792(00)90110-2 [pii]

Dunn, A. L., Trivedi, M. H., Kampert, J. B., Clark, C. G., \& Chambliss, H. O. (2005). Exercise treatment for depression: Efficacy and dose response. American Journal of Preventive Medicine, 28(1), 1-8. doi:S0749-3797(04)00241-7 [doi] 
Fietze, I., Strauch, J., Holzhausen, M., Glos, M., Theobald, C., Lehnkering, H., \& Penzel, T. (2009). Sleep quality in professional ballet dancers. Chronobiology International, 26(6), 1249-1262. doi:10.3109/07420520903221319 [doi]

Flausino, N. H., Da Silva Prado, J. M., de Queiroz, S. S., Tufik, S., \& de Mello, M. T. (2012). Physical exercise performed before bedtime improves the sleep pattern of healthy young good sleepers. Psychophysiology, 49(2), 186-192. doi:10.1111/j.14698986.2011.01300.x [doi]

Fry, R. W., Morton, A. R., \& Keast, D. (1991). Overtraining in athletes. an update. Sports Medicine (Auckland, N.Z.), 12(1), 32-65.

Garth, A. K., \& Burke, L. M. (2013). What do athletes drink during competitive sporting activities? Sports Medicine (Auckland, N.Z.), 43(7), 539-564. doi:10.1007/s40279-0130028-y [doi]

Halson, S. (2013). Nutritional interventions to enhance sleep. Sports Science Exchange, 26(116), 1-5.

Halson, S. L., Bridge, M. W., Meeusen, R., Busschaert, B., Gleeson, M., Jones, D. A., \& Jeukendrup, A. E. (2002). Time course of performance changes and fatigue markers during intensified training in trained cyclists. Journal of Applied Physiology (Bethesda, Md.: 1985), 93(3), 947-956. doi:10.1152/japplphysiol.01164.2001 [doi]

Halson, S. L., Lancaster, G. I., Achten, J., Gleeson, M., \& Jeukendrup, A. E. (2004). Effects of carbohydrate supplementation on performance and carbohydrate oxidation after intensified cycling training. Journal of Applied Physiology (Bethesda, Md.: 1985), 97(4), 1245-1253. doi:10.1152/japplphysiol.01368.2003 [doi] 
Halson, S. L., Lancaster, G. I., Jeukendrup, A. E., \& Gleeson, M. (2003). Immunological responses to overreaching in cyclists. Medicine and Science in Sports and Exercise, 35(5), 854-861. doi:10.1249/01.MSS.0000064964.80040.E9 [doi]

Hartmann, M. K., Crisp, A. H., Evans, G., Gaitonde, M. K., \& Kirkwood, B. R. (1979). Short-term effects of $\mathrm{CHO}$, fat and protein loads on total tryptophan/tyrosine levels in plasma as related to \% REM sleep. Waking and Sleeping, 3(1), 63-68.

Hausswirth, C., Louis, J., Aubry, A., Bonnet, G., Duffield, R., \& LE Meur, Y. (2014). Evidence of disturbed sleep and increased illness in overreached endurance athletes. Medicine and Science in Sports and Exercise, 46(5), 1036-1045. doi:10.1249/MSS.0000000000000177 [doi]

Jacobs, K. A., \& Sherman, W. M. (1999). The efficacy of carbohydrate supplementation and chronic high- carbohydrate diets for improving endurance performance. International Journal of Sport Nutrition, 9(1), 92-115.

Jeukendrup, A. E. (2013). The new carbohydrate intake recommendations. Nestle Nutrition Institute Workshop Series., 75, 63-71.

Jeukendrup, A. (2014). A step towards personalized sports nutrition: Carbohydrate intake during exercise. Sports Medicine (Auckland, N.Z.), 44 Suppl 1, 25-33. doi:10.1007/s40279-014-0148-z [doi]

Jeukendrup, A. E. (2011). Nutrition for endurance sports: Marathon, triathlon, and road cycling. Journal of Sports Sciences, 29 Suppl 1, S91-9. doi:10.1080/02640414.2011.610348 [doi]

Jeukendrup, A. E., Hesselink, M. K., Snyder, A. C., Kuipers, H., \& Keizer, H. A. (1992). Physiological changes in male competitive cyclists after two weeks of intensified 
training. International Journal of Sports Medicine, 13(7), 534-541. doi:10.1055/s2007-1021312 [doi]

Jurimae, J., Maestu, J., Purge, P., \& Jurimae, T. (2004). Changes in stress and recovery after heavy training in rowers. Journal of Science and Medicine in Sport / Sports Medicine Australia, 7(3), 335-339.

Kentta, G., \& Hassmen, P. (1998). Overtraining and recovery. A conceptual model. Sports Medicine (Auckland, N.Z.), 26(1), 1-16.

Kubitz, K. A., Landers, D. M., Petruzzello, S. J., \& Han, M. (1996). The effects of acute and chronic exercise on sleep. A meta-analytic review. Sports Medicine (Auckland, N.Z.), 21(4), 277-291.

Kuipers, H., \& Keizer, H. A. (1988). Overtraining in elite athletes. review and directions for the future. Sports Medicine (Auckland, N.Z.), 6(2), 79-92.

Leeder, J., Glaister, M., Pizzoferro, K., Dawson, J., \& Pedlar, C. (2012). Sleep duration and quality in elite athletes measured using wristwatch actigraphy. Journal of Sports Sciences, 30(6), 541-545. doi:10.1080/02640414.2012.660188 [doi]

Maughan, R. J., \& Burke, L. (2012). Nutrition for athletes. International Olympic Committee,

Meeusen, R., Duclos, M., Foster, C., Fry, A., Gleeson, M., Nieman, D., . . A American College of Sports Medicine. (2013). Prevention, diagnosis, and treatment of the overtraining syndrome: Joint consensus statement of the European college of sport science and the American college of sports medicine. Medicine and Science in Sports and Exercise, 45(1), 186-205. doi:10.1249/MSS.0b013e318279a10a [doi] 
Morgan, W. P., Brown, D. R., Raglin, J. S., O'Connor, P. J., \& Ellickson, K. A. (1987). Psychological monitoring of overtraining and staleness. British Journal of Sports Medicine, 21(3), 107-114.

Morgan, W. P., Costill, D. L., Flynn, M. G., Raglin, J. S., \& O'Connor, P. J. (1988). Mood disturbance following increased training in swimmers. Medicine and Science in Sports and Exercise, 20(4), 408-414.

Myllymaki, T., Kyrolainen, H., Savolainen, K., Hokka, L., Jakonen, R., Juuti, T., . . Rusko, H. (2011). Effects of vigorous late-night exercise on sleep quality and cardiac autonomic activity. Journal of Sleep Research, 20(1 Pt 2), 146-153. doi:10.1111/j.1365-2869.2010.00874.x [doi]

O'Connor, P. J., Breus, M. J., \& Youngstedt, S. D. (1998). Exercise-induced increase in core temperature does not disrupt a behavioral measure of sleep. Physiology \& Behavior, 64(3), 213-217. doi:S0031-9384(98)00049-3 [pii]

Phillips, F., Chen, C. N., Crisp, A. H., Koval, J., McGuinness, B., Kalucy, R. S., . . Lacey, J. H. (1975). Isocaloric diet changes and electroencephalographic sleep. Lancet, 2(7938), 723-725. doi:S0140-6736(75)90718-7 [doi]

Pilcher, J. J., \& Huffcutt, A. I. (1996). Effects of sleep deprivation on performance: A metaanalysis. Sleep, 19(4), 318-326.

Porter, J. M., \& Horne, J. A. (1981). Bed-time food supplements and sleep: Effects of different carbohydrate levels. Electroencephalography and Clinical Neurophysiology, 51(4), 426-433.

Raglin, J. S., \& Morgan, W. P. (1994). Development of a scale for use in monitoring training-induced distress in athletes. International Journal of Sports Medicine, 15(2), 84-88. doi:10.1055/s-2007-1021025 [doi] 
Reilly, T., \& Edwards, B. (2007). Altered sleep-wake cycles and physical performance in athletes. Physiology \& Behavior, 90(2-3), 274-284. doi:S0031-9384(06)00396-9 [pii]

Rhea, M. R., \& Alderman, B. L. (2004). A meta-analysis of periodized versus nonperiodized strength and power training programs. Research Quarterly for Exercise and Sport, 75(4), 413-422.

Sadeh, A. (2011). The role and validity of actigraphy in sleep medicine: An update. Sleep Medicine Reviews, 15(4), 259-267. doi:10.1016/j.smrv.2010.10.001 [doi]

Samuels, C. (2008). Sleep, recovery, and performance: The new frontier in highperformance athletics. Neurologic Clinics, 26(1), 169-80; ix-x. doi:10.1016/j.ncl.2007.11.012 [doi]

Sherman, W. M., Doyle, J. A., Lamb, D. R., \& Strauss, R. H. (1993). Dietary carbohydrate, muscle glycogen, and exercise performance during $7 \mathrm{~d}$ of training. The American Journal of Clinical Nutrition, 57(1), 27-31.

Souissi, M., Chtourou, H., Zrane, A., Cheikh, R. B., Dogui, M., Tabka, S., \& Souissi, N. (2011). Effect of time-of-day of aerobic maximal exercise on the sleep quality of trained subjects. Biological Rhythm Research, 43(3), 323-330.

Spiegel, K., Leproult, R., \& Van Cauter, E. (1999). Impact of sleep debt on metabolic and endocrine function. Lancet, 354(9188), 1435-1439. doi:S0140-6736(99)01376-8 [doi]

Taylor, S. R., Rogers, G. G., \& Driver, H. S. (1997). Effects of training volume on sleep, psychological, and selected physiological profiles of elite female swimmers. Medicine and Science in Sports and Exercise, 29(5), 688-693. 
Uchida, S., Shioda, K., Morita, Y., Kubota, C., Ganeko, M., \& Takeda, N. (2012). Exercise effects on sleep physiology. Frontiers in Neurology, 3, 48.

doi:10.3389/fneur.2012.00048 [doi]

Vuori, I., Urponen, H., Hasan, J., \& Partinen, M. (1988). Epidemiology of execise effecrs on sleep. Acta Physiol Scand Suppl, 574, 3-7.

Witard, O. C., Jackman, S. R., Kies, A. K., Jeukendrup, A. E., \& Tipton, K. D. (2011). Effect of increased dietary protein on tolerance to intensified training. Medicine and Science in Sports and Exercise, 43(4), 598-607. doi:10.1249/MSS.0b013e3181f684c9 [doi]

Youngstedt, S. D., \& Kline, C., E. (2006).

Epidemiology of exercise and sleep Sleep and Biological Rhythms, 4(215), 221.

Youngstedt, S. D., O'Connor, P. J., \& Dishman, R. K. (1997). The effects of acute exercise on sleep: A quantitative synthesis. Sleep, 20(3), 203-214.

Zammit, G. K., Kolevzon, A., Fauci, M., Shindledecker, R., \& Ackerman, S. (1995). Postprandial sleep in healthy men. Sleep, 18(4), 229-231. 


\section{$\underline{\text { Figure Captions }}$}

Figure 1: Change in sleep parameters from baseline over the period of intensified training (IT) in the high carbohydrate (HCHO) and control (CON) trials. Black circles represent $H C H O$ and white circles represent CON. Data are mean \pm SE. * Indicates significant increase with time $(p<0.05)$.

Figure 2: Changes in sleep efficiency from baseline over the period of intensified training (IT) in the high carbohydrate (HCHO) and control (CON) trials. Black circles represent $H C H O$ and white circles represent CON. Data are mean $\pm S E$. * Indicates significant decrease with time $(p<0.05)$.

Figures 3\&4: Daily changes in Profile of Mood States - 24 item questionnaire (POMS-24) (Figure 6) and changes in the number of ' $a$ ' scores from the Daily Analysis of Lifestyle Demands on Athletes (DALDA) - part B (figure 7) from baseline over the period of intensified training (IT) in the high carbohydrate (HCHO) and control (CON) trials. Black circles represent $\mathrm{HCHO}$ and white circles represent CON. Data are mean $\pm S E$. * Indicates significant increase with time ( $p<0.05)$.

Figure 5: Change in resting morning heart rate (HR) from baseline over IT in the high carbohydrate (HCHO) and control (CON) trials. Black circles represent $\mathrm{HCHO}$ and white circles represent CON. Data are mean $\pm S E$. $\dagger$ Indicates significant difference between conditions $(p<0.05)$. 
Figure 1
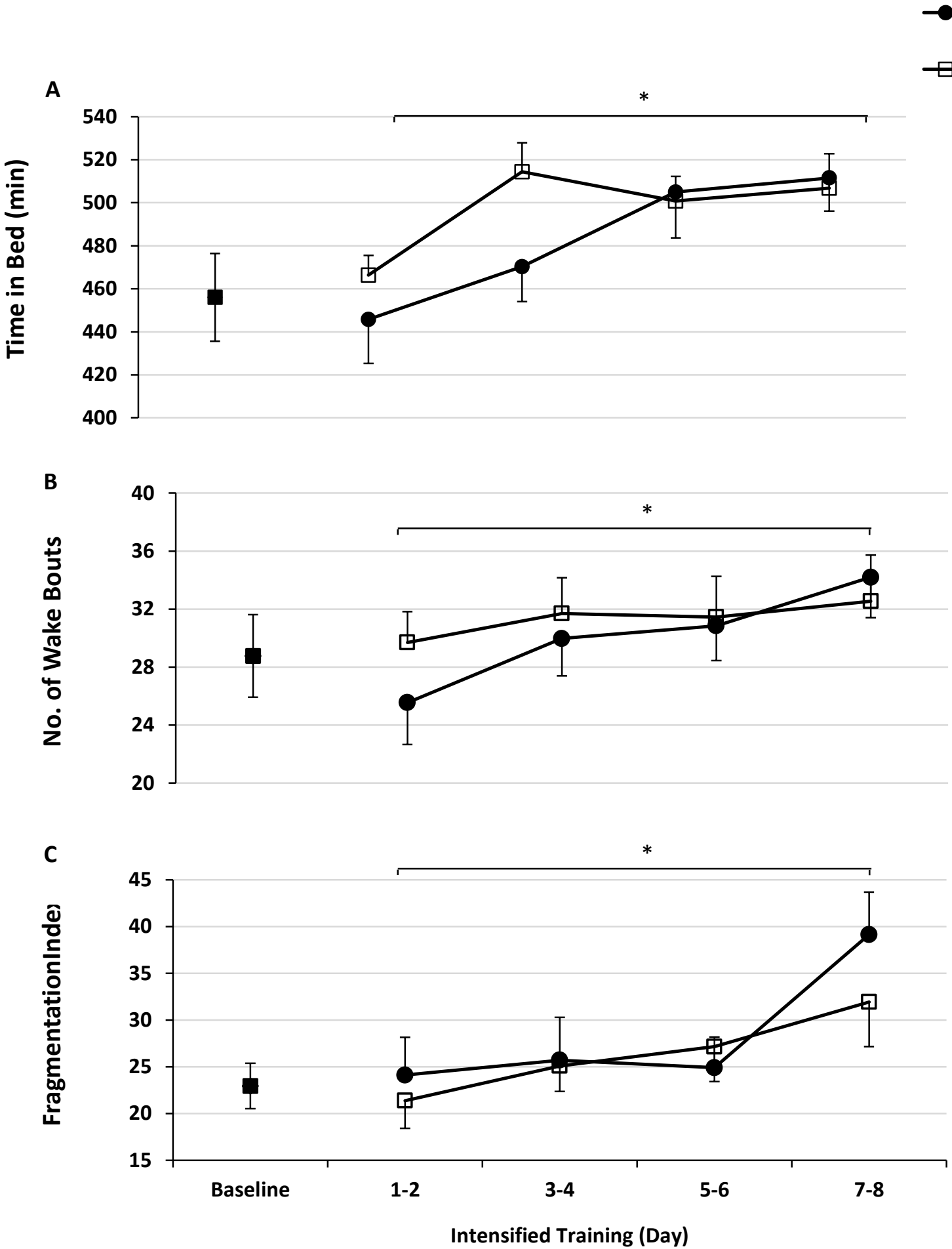
Figure 2

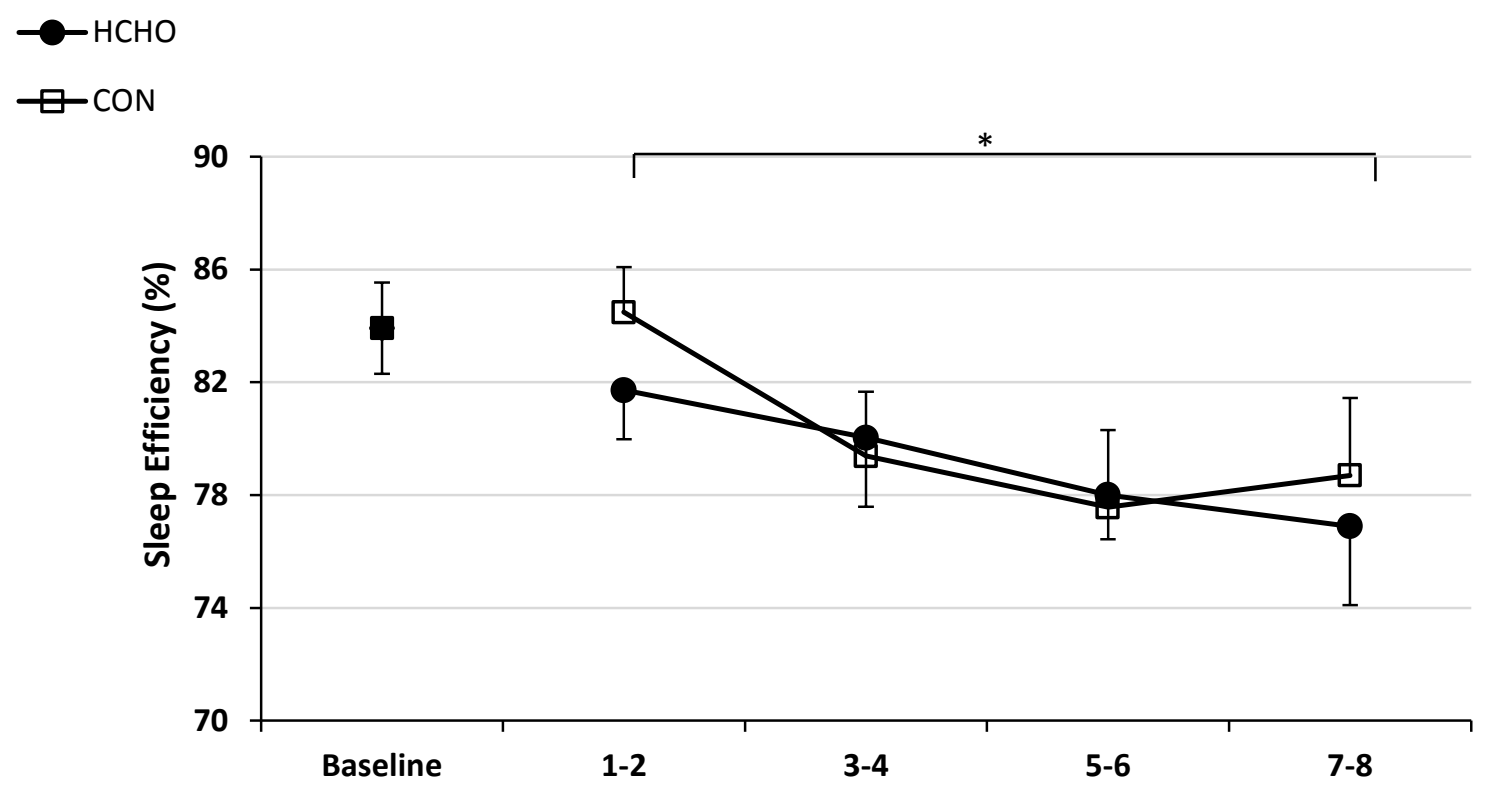


Figure 3

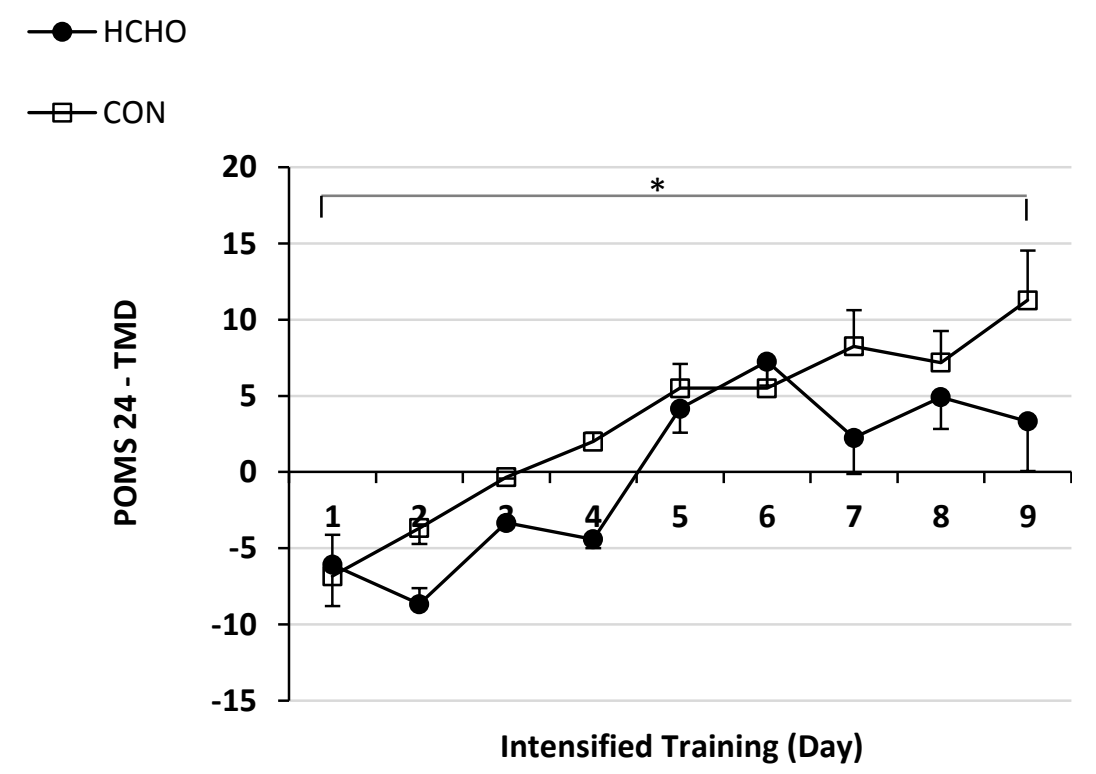

Figure 4

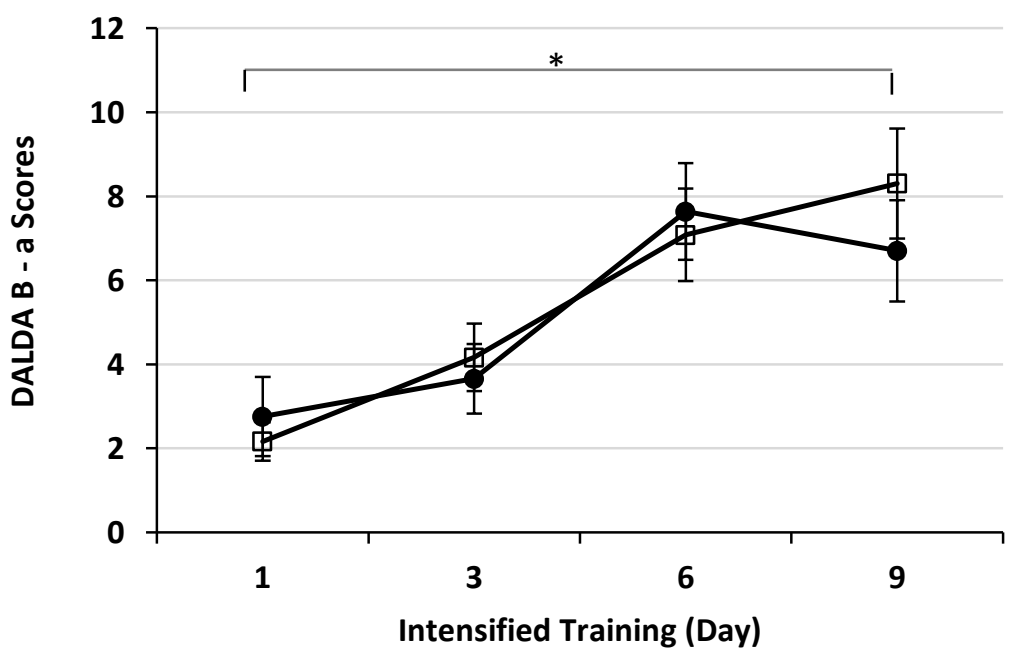


Figure 5

- - $\mathrm{HCHO}$

曰CON

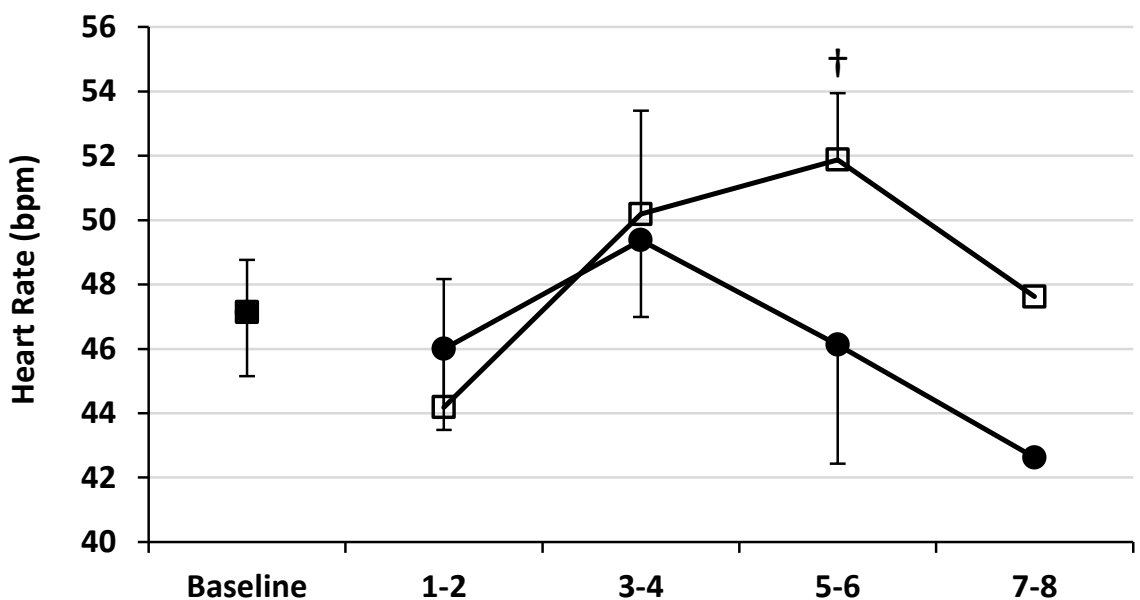

